\title{
Sample Adequacy Controls for Infectious Disease Diagnosis by Oral Swabbing
}

\author{
Meagan Deviaene
}

\begin{abstract}
A thesis
Submitted in partial fulfillment of the requirements of the degree of

Master of Science
\end{abstract}

University of Washington

2017

Committee:

Gerard Cangelosi

Lisa Jones-Engel

Peter Rabinowitz

Program Authorized to Offer Degree:

School of Public Health - Department of Environmental and Occupational Health Sciences 
Meagan Deviaene 


\title{
University of Washington
}

\author{
ABSTRACT \\ Oral Swab Analysis for diagnosis of Tuberculosis: Quality Assurance Implications and One \\ Health Applications \\ Chair of the Supervisory Committee: \\ Professor Gerard Cangelosi \\ Department of Environmental and Occupational Health Sciences
}

Oral swabs are emerging as a non-invasive sampling method for diagnosis of infectious diseases such as Ebola and tuberculosis. This project evaluated quality assurance strategies to assure proper sample collection. Two sample adequacy controls (SAC) that detect substances that are differentially present in properly versus improperly collected samples were assessed. One control detected oral microbial flora (Streptococcus species DNA) and the other, human cells (human mitochondrial DNA, mtDNA). Quantitative PCR (qPCR) assays for the two targets were applied to swabs of buccal and hand regions (representing properly improperly collected samples, respectively) collected from 51 healthy human volunteers in Seattle, WA, USA. Quantification cycle $(\mathrm{Cq})$ cutoffs that maximized Youden's index were established for each assay. The streptococcal target at a Cq cutoff of 34.9 had $99.0 \%$ sensitivity and specificity, whereas human mtDNA perfectly distinguished between hand and mouth swabs at $\mathrm{Cq}=31.3$. The mtDNA test was then applied to buccal, tongue, and gum swabs collected from suspected tuberculosis patients in Worcester, South Africa. The three oral sites yielded indistinguishable amounts of human mtDNA, however PurFlock ${ }^{\mathrm{TM}}$ swabs collected slightly more human DNA than OmniSwabs $^{\mathrm{TM}}(\mathrm{p}=0.035)$. Participant characteristics such as HIV status, TB status and gender did not influence Cq values for any swab type or mouth region. Quantitative PCR detection of 
human mtDNA can reliably distinguish proper sample collection from casual skin contact, and thereby serve as a sample adequacy control for oral swab-based diagnostics.

\section{TABLE OF CONTENTS}

\section{BACKGROUND}

A. ORAL SWAB DIAGNOSTICS FOR INFECTIOUS DISEASE

B. ORAL SWAB ANALYSIS FOR TUBERCULOSIS

C. QUALiTy ASSURance In Diagnostic TeStS

2. PROJECT OVERVIEW

AIM 1: COMPARISON OF TWO CANDIDATE SAMPLE ADEQUACY CONTROL ASSAYS AIM 2: IMPLEMENTATION OF SAMPLE ADEQUACY CONTROL ASSAY IN A CLINICAL COHORT

3. RESULTS AND DISCUSSION

AIM 1: COMPARISON OF TWO CANDIDATE SAMPLE ADEQUACY CONTROL ASSAYS

AIM 2: IMPLEMENTATION OF SAMPLE ADEQUACY CONTROL ASSAY IN A CLINICAL COHORT

4. MATERIALS AND METHODS

5. REFERENCES

APPENDIX A. NASAL SWABS FOR DETECTION OF BOVINE TUBERCULOSIS

A. BACKGROUND

B. METHODS

C. RESUlTS AND DiscuSSION 22 


\section{BACKGROUND}

\section{a. Oral Swab Diagnostics for Infectious disease}

Communicable or infectious diseases continue to represent one of the greatest causes of global morbidity. According to the WHO, communicable or maternal causes contribute to $31 \%$ of global disability adjusted life years (one DALY is equivalent to the loss of one year of health). ${ }^{1}$ Control or eradication of the infectious disease burden will require robust diagnostics. Oral swabs can provide a non-invasive, inexpensive, and easy-to-use sampling strategy for infection diagnosis. An oral swab is a sample taken by brushing a swab on a surface within the mouth, such as the buccal mucosa (inner cheek), tongue or gums. Paired with an appropriate assay, the matrix collected by oral swabs can serve as an excellent diagnostic matrix aiding to overcome many issues facing infectious disease diagnostics.

Oral swabs have been employed, either in clinical or experimental contexts, to detect diverse infectious diseases, such as TB, hepatitis C, human immunodeficiency virus and Streptococci bacteria in both humans and animals..$^{2-7}$ They can be used to evaluate the underlying prevalence of a disease in a population. For example, a study used oral swabs to detect and type oral human papilloma virus (HPV) in nearly 6,000 healthy adults in China. ${ }^{8}$ Oral swabs can also be employed in active case finding approaches, as carried out by Aschar et al in detection leishmaniasis in canines. ${ }^{9}$ Finally they can be incorporated into clinical contexts as a stand-alone method or to supplement clinical diagnosis. Oral swab testing played a highly significant role in the medical and public health response to the 2014-2016 Ebola outbreak in West Africa and elsewhere. $^{10}$ 


\section{b. Oral Swab analysis for Tuberculosis}

The need for a simple, sensitive and inexpensive diagnostic test for tuberculosis is especially critical. Tuberculosis is an infectious disease caused by the bacterium Mycobacterium tuberculosis. It currently accounts for $1.64 \%$ of global DALYs. (IHME) It usually manifests as a pulmonary infection, but can also affect other body sites in an infection state known as extrapulmonary TB. Tuberculosis infection has two key stages, a latent stage, in which the infected individual has been exposed to tuberculosis and will test positive in an immunoassay, but is not symptomatic and an active stage in which the individual is symptomatic and may transmit infection by coughing or other aerosolization of infectious particles. ${ }^{11}$ The global burden of infection in 2015 was between 2-3 billion with 22 high-burden countries accounting for $80 \%$ of TB cases. ${ }^{12}$ The density of infected individuals points to the utility of active case finding to help identify individuals for treatment and prevent new infections. This is especially important considering the lack of an effective vaccine, and the difficulties in treating active infection.

Currently used diagnostic methods for TB detection in humans include smear-or-culture confirmation and the automated PCR-based test GeneXpert MTB/RIF. GeneXpert has been replacing the smear-or-culture methods since its introduction in 2010 with $69 \%$ of countries reporting national policy being use of the Xpert as the initial diagnostic test for people at risk for drug-resistant TB, and $60 \%$ for the initial test for those with HIV. ${ }^{12}$ Sputum is the most commonly used diagnostic matrix in these tests. In some cases, when sputum cannot be expelled routinely its production is induced, which is invasive, especially in ill individuals and young children. 
Oral Swab Analysis (OSA) is a tuberculosis diagnostic method that continues to be evaluated in different study populations. For many years, Lisa Jones-Engel and others used oral swabs as a method of detection for tuberculosis and other diseases in non-human primates. ${ }^{2,13-15}$ The method operates on the hypothesis that Mycobacterium tuberculosis bacilli adhere to surfaces of oral mucosa, and thus can be detected through the collection of this matrix with an oral swab. When this method was adapted by Wood et al to test for TB in humans, it was found to have a sensitivity of $90 \%$ in a cohort of TB suspects in South Africa and 100\% specificity in healthy, TB negative Seattle controls. ${ }^{16}$ Ongoing clinical evaluations of OSA indicate a diagnostic performance of $92 \%$ sensitivity and $92 \%$ specificity relative to sputum Xpert by subject. (Luabeya, unpublished results). If diagnostic performance of OSA is shown to be comparable to the current diagnostic gold standard methods, OSA could present a cost effective and noninvasive alternative or supplement in tuberculosis diagnostics.

\section{c. Quality Assurance In Diagnostic Tests}

Quality assurance in molecular diagnostic tests is important for both evaluation and implementation of diagnostic test methods. There are many different components of a quality assurance program, including personnel training, facilities, and reagent requirements. There are also many types of assay controls ${ }^{17}$ with different goals in mind, such as:

1) Positive reference material controls in the form of the specimen in question known to contain the organism, whole organisms, or purified DNA organism of interest. These materials are usually "spiked" into the matrix material and run alongside diagnostic samples in molecular tests to validate that the extraction and $\mathrm{qPCR}$ processes have not 
failed.

2) Negative Controls consisting of a sample buffer devoid of DNA products to ensure laboratory contamination is not the causing false positive results.

3) Internal or Inhibition controls which can be homologous or heterologous targets analyzed alongside the diagnostic sequence to ascertain whether inhibitive elements are hindering the molecular reaction and giving false negative results.

4) Sampling adequacy or endogenous positive controls defined here as a molecular target which differs from the diagnostic target and should be abundant in a properly collected sample while limited or absent in an improperly collected sample. These controls address the issue of sampling adequacy, and can also provide validation that laboratory analyses have not failed (as do reference material controls).

Despite the recognition of the importance of a proper quality assurance plan for diagnostic tests, there are still gaps in their adoption. First, of the positive control types, the most standardized and available information applies to reference positive controls. Under the clinical laboratory improvement amendments regulation, the CDC provides publically available databases with over 30 infectious disease reference materials and their ordering information. (https://wwwn.cdc.gov/clia/Resources/GetRM/GetRM_ID.aspx\#ttabs_id_1)

Even among clinical diagnostic tests, adoption of sampling adequacy controls can vary. This tendency is illustrated by two FDA approved diagnostic assays for carcinogenic HPV typing for colposcopy referral and screening, the Digene Hybrid Capture 2 (HC2) HPV DNA test and the Cervista HPV HR assay. ${ }^{18}$ The former, while more widely adopted lacks an internal control to 
evaluate sample adequacy or inhibition, while the latter incorporates detection of histone DNA as an endogenous control.

The previous example compares two diagnostic tests implemented mostly in clinical settings. In different settings and stages of diagnostic tests, use of inhibition or sampling adequacy controls is even more variable. By requirement, clinical or medical settings often have well defined and thorough quality control plans in place, and multiple both internationally and nationally accredited tests exist. The issue becomes somewhat more complicated in a research setting, where tests that are not yet approved, are being evaluated. Endogenous controls have been implemented in some studies, especially those in animals, ${ }^{2,19}$ but in diagnostic tests for humans they are sometimes employed without previous validation. For example, in a recent report on oral swab testing for Ebola virus, characteristics of human hydroxymethylbilane synthase (HMBS) DNA used as an endogenous positive control were reported, however no determination of the amount of such DNA that constitutes a properly collected sample was presented. ${ }^{20}$

\section{PROJECT OVERVIEW}

One of the phases of this project evaluated different endogenous control candidates for oral swab diagnostics. The goal in implementing an endogenous positive control was to be able to identify false negative results caused by inadequate sampling (insufficient contact with oral mucosa). In contrast to samples such as sputum and blood, which can be inspected visually to assure proper collection, improperly collected oral swabs are visually indistinguishable from properly collected swabs. 
Many candidate assays were considered (Table 1), including molecular assays, DNA quantitation assays, and colorimetric reactions such as the Bradford assay or the starch-iodine reactions that target both mouth-specific or simply human specific molecules. Molecular assays were selected in the end for several reasons. First, the transport/storage buffer for which OSA was optimized is composed of 50mM of EDTA and sucrose, $100 \mathrm{mM}$ sodium chloride, $65 \mathrm{mM}$ tris, and $0.3 \%$ SDS. Some of these components, and especially the SDS, rendered many of the chemical or enzymatic processes necessary for colorimetric quantification impossible. Molecular assays also offer the benefit of easy integration into the laboratory analyses currently in place for OSA. Two qPCR assays were finally selected for comparison.

One candidate qPCR positive control made use of the growing knowledge on the human oral microbiome. The oral cavity is rich in bacteria, with over 700 species identified. ${ }^{16}$ Despite this internal species diversity, the oral microbiome has one of the lowest levels of beta diversity, or diversity between individuals. ${ }^{17}$ Because the microbial community that comprises the oral microbiome is largely conserved person to person, it is a good candidate as a biomarker for mouth contact. Streptococcus is one of the core genera of the oral microbiome ${ }^{18}$ and the candidate positive control test targeted species of this genus.

The second approach targeted a ubiquitous human mitochondrial gene. Human housekeeping genes are often used in genetic studies to standardize gene expression differences. They have been used in some infectious disease diagnostic tests, ${ }^{19-21}$ most often to ensure inhibition is not occurring in the qPCR amplification, rather than for the purpose of ascertaining sampling adequacy. ${ }^{11}$ 
Table 1. Summary of assays considered as sample adequacy controls, including whether they were successfully attempted, and benefits and challenges in their implementation

\begin{tabular}{|c|c|c|c|c|c|c|}
\hline Test & Type & $\begin{array}{l}\text { Attempt/ } \\
\text { Success }\end{array}$ & & Principle & Potential advantages & Potential limitations \\
\hline $\begin{array}{l}\text { Starch } \\
\text { iodine }\end{array}$ & $\begin{array}{l}\text { Colorimetric } \\
\text { reaction }\end{array}$ & yes & no & $\begin{array}{l}\text { Iodine and starch form a complex, } \\
\text { Amylase degrades starch, changing color }\end{array}$ & Easy, saliva specific & $\begin{array}{l}\text { Impossible due to } \\
\text { chemistry of buffer }\end{array}$ \\
\hline Amylase & $\begin{array}{l}\text { Colorimetric } \\
\text { reaction }\end{array}$ & yes & no & $\begin{array}{l}\text { Colorimetric agents attached to starch } \\
\text { become released when cleaved by } \\
\text { amylase and induce a color change in } \\
\text { suspension buffer }\end{array}$ & Easy, saliva specific & $\begin{array}{l}\text { Impossible due to } \\
\text { chemistry of buffer }\end{array}$ \\
\hline Strep & qPCR & yes & yes & $\begin{array}{l}\text { Streptococci are the principal } \\
\text { constituents of the oral microbiome }\end{array}$ & $\begin{array}{l}\text { Mouth specific, Potential to } \\
\text { duplex on current assay, } \\
\text { extraction validation }\end{array}$ & $\begin{array}{l}\text { Novel, no standardized } \\
\text { test to draw from }\end{array}$ \\
\hline mRNA & RT-PCR & no & $\mathrm{n} / \mathrm{a}$ & $\begin{array}{l}\text { There is an oral transcriptome that differs } \\
\text { from other body sites }\end{array}$ & $\begin{array}{l}\text { Potential to be mouth } \\
\text { region specific }\end{array}$ & Different PCR type \\
\hline Nano drop & dsDNA quant & yes & yes & $\begin{array}{l}\text { Samples properly taken in the oral cavity } \\
\text { will have a higher amount of } \\
\text { biomaterials, including DNA present }\end{array}$ & Uses minimal sample & $\begin{array}{l}\text { Time consuming, } \\
\text { potential for high sample } \\
\text { type variability }\end{array}$ \\
\hline Quant-IT & dsDNA quant & no & $\mathrm{n} / \mathrm{a}$ & $\begin{array}{l}\text { Samples properly taken in the oral cavity } \\
\text { will have a higher amount of } \\
\text { biomaterials, including DNA present }\end{array}$ & Uses minimal sample & Not mouth specific \\
\hline Bradford & $\begin{array}{l}\text { Colormetric } \\
\text { rxn }\end{array}$ & yes & no & $\begin{array}{l}\text { Absorbance shift of Coomassie blue dye } \\
\text { when complexed to components of } \\
\text { protein }\end{array}$ & Easy & $\begin{array}{l}\text { Impossible due to } \\
\text { chemistry of buffer }\end{array}$ \\
\hline $\begin{array}{l}\text { Human } \\
\text { DNA }\end{array}$ & qPCR & yes & yes & $\begin{array}{l}\text { human housekeeping genes should be } \\
\text { present in higher number in properly } \\
\text { collected sample }\end{array}$ & $\begin{array}{l}\text { Common practice in tests } \\
\text { similar to OSA, validated in } \\
\text { these }\end{array}$ & Not mouth specific \\
\hline
\end{tabular}


Aim 1: Comparison of two candidate Sample Adequacy Control assays

Task 1A) Calculate a Cq threshold for each assay by employing Youden's index

Hypothesis: Cq values yielded from mouth swabs as compared to hand swabs will be sufficiently different to enable the establishment of a threshold value separating the two groups in the case of both assays

Task 1B) Compare performance (sensitivity and specificity) of the respective assays at the cutoff

Hypothesis: Streptococcal qPCR will distinguish properly from improperly collected swabs with better specificity than human mtDNA qPCR due to detecting a mouth specific target

To compare two candidate qPCR positive control assays, a paired study was undertaken in Seattle, WA. The design was paired in two senses. First, two qPCR assays were performed on the same samples. Second, hand swabs were collected in addition to mouth swabs. Hand swabs were used as simulated mishandled swabs that incidentally contacted human skin outside of the mouth. Such swabs are expected to contain both human and streptococcal DNA, because of the ubiquity of both on skin and in environments where people are present. Since a lower Cq value in qPCR indicates greater gene target amount, we tested the hypothesis that $\mathrm{Cq}$ values yielded from mouth swabs as compared to hand swabs would be sufficiently different to enable the establishment of a threshold value separating the two groups.

Aim 2: Implementation of Sample Adequacy control assay in a clinical cohort An optimized method utilizing human mtDNA was then applied to oral swabs collected a cohort 
in Worcester, South Africa. Swab samples were collected from these participants in different mouth regions and with different swab types as part of an ongoing analysis of oral swab testing for testing for tuberculosis. First, it was ascertained whether $\mathrm{Cq}$ values garnered from the Seattle participants would be comparable to those from South African participants who had been adequately sampled. Secondly, paired T-tests were carried out to test the hypothesis that the same $\mathrm{Cq}$ (and thus amounts of human mtDNA) was garnered from all mouth regions (tongue, gums and buccal mucosa) and irrelevant of swab type (OmniSwab or Purflock swab)

Task 2A) Compare performance of chosen assay between Seattle cohort and clinical cohort Hypothesis: There will be no differences in buccal swab Cq values from Seattle as compared to South Africa participants.

Task 2B) Comparison of different swab types and different mouth regions for their ability to collect diagnostic matrix

Hypothesis: There will not be any significant differences in Cq vales based on swab type or mouth region

\section{RESULTS AND DISCUSSION}

Aim 1: Comparison of two candidate Sample Adequacy Control assays

For the Seattle-based portion of the study, 51 subjects were enrolled and 4 OmniSwabs were collected from each participant: One from each hand, and 1 from each inner cheek. Additionally, an air control swab which constitutes a swab exposed to air for five seconds to act as a negative control, was taken during the participants' swabbing. Cq values (inversely proportional to target quantity) from all 255 samples and for each qPCR test $(\mathrm{n}=510)$ were compared. Mouth and hand swab Cqs are summarized in Figure 1. A Cq cutoff value that maximized Youden's index 
([sensitivity + specificity]-1) was established for each assay. The streptococcal qPCR's optimal Cq cutoff was 34.9 , with of sensitivity of $99.0 \%$ and specificity of $99.0 \%$. Human mtDNA as a classifier was able to perfectly distinguish between hand and mouth samples at a threshold $\mathrm{Cq}$ value of 31.3. To further determine which test was superior in resolving between mouth and hand swabs, a paired T-test was performed for the mean differences between the threshold and each subject's hand or mouth Cq value. The mean differences from the threshold for Cq values yielded from streptococcal qPCR were significantly less than those from the mitochondrial qPCR ( $p=$ $0.00017, \mathrm{H}_{\mathrm{A}}=$ two-sided).

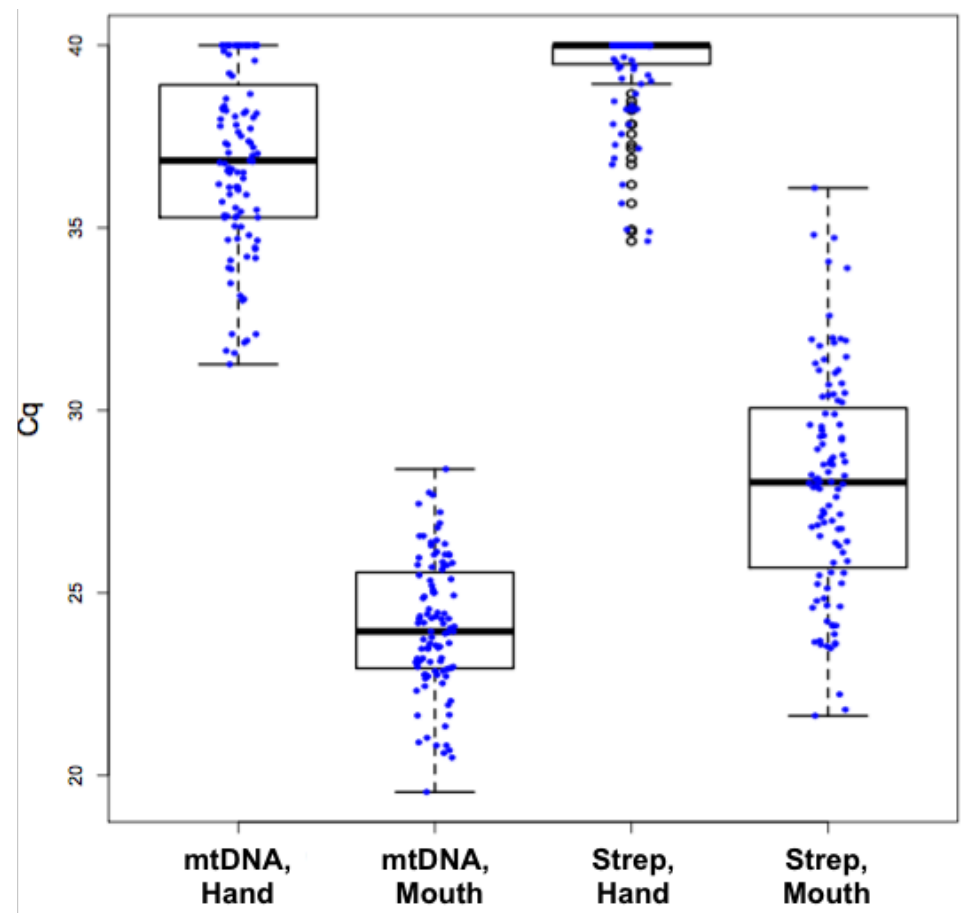

Figure 1. Hand (improperly collected) swab and mouth (properly collected) swab Cq comparisons for human mtDNA as compared to Streptococcal DNA qPCR

While both candidate tests appear able to distinguish mouth swabs from hand swabs, the qPCR test targeting human mtDNA outperformed the assay targeting the Streptococcus genus. This was largely due to the more variable and higher overall $\mathrm{Cq}$ values observed when mouth swabs were tested by the streptococcal assay. The variation that has been reported in the oral microbiome between individuals with different diets or health states is a possible explanation for this observation. ${ }^{21-23}$ Lifestyle and health information was not gathered, thus it cannot be determined 
if the high Cq values observed in this cohort were associated with any of these conditions. When results from hand swabs alone are compared between the two different methods, the human mtDNA assay yielded lower overall Cqs than did the streptococcal assay. The higher mtDNA Cq values seen from hand samples as compared to mouth swabs most likely reflect the swab's propensity to collect material from the mouth versus hands.

Though the use of a human housekeeping gene target as a sample adequacy control showed more promise in this evaluation, considering the small difference in performance between the two methods and ongoing advances in sequencing and characterizing the human microbiome, a sampling adequacy qPCR assay targeting microbes can likely be improved.

\section{Aim 2: Implementation of Sample Adequacy control assay in a clinical cohort}

The human mtDNA sample adequacy control was then applied to samples collected from a South African clinical cohort that is participating in an ongoing evaluation of Oral Swab Analysis (OSA) as a diagnostic test for TB (http://deohs.washington.edu/tuberculosis-case-finding). In this study, 175 suspected TB subjects and 70 healthy control subjects in South Africa were tested for TB by collecting oral swabs on 3 different swabbing occasions. The present study focused on swabs taken from participants during their second swabbing session. The swabs collected from the participants included a tongue, gum, and right buccal sample collected with OmniSwabs ${ }^{\mathrm{TM}}$, a left buccal sample taken with a PurFlock ${ }^{\mathrm{TM}}$ swab and an air control (taken in a similar manner as those in phase 1) for a total of five swabs per subject.

First, comparing Buccal OmniSwabs ${ }^{\mathrm{TM}}$ from South African participants and Seattle participants (Figure 2), Cq values were significantly different $\left(\mathrm{H}_{\mathrm{A}}=\right.$ two-sided, $\left.\mathrm{p}=0.0016\right)$. This difference 
may reflect disparities in sampling methodologies. Swabbing duration for South African participants was 10 seconds, somewhat longer than for the participants in the Seattle phase of this study (5 seconds).

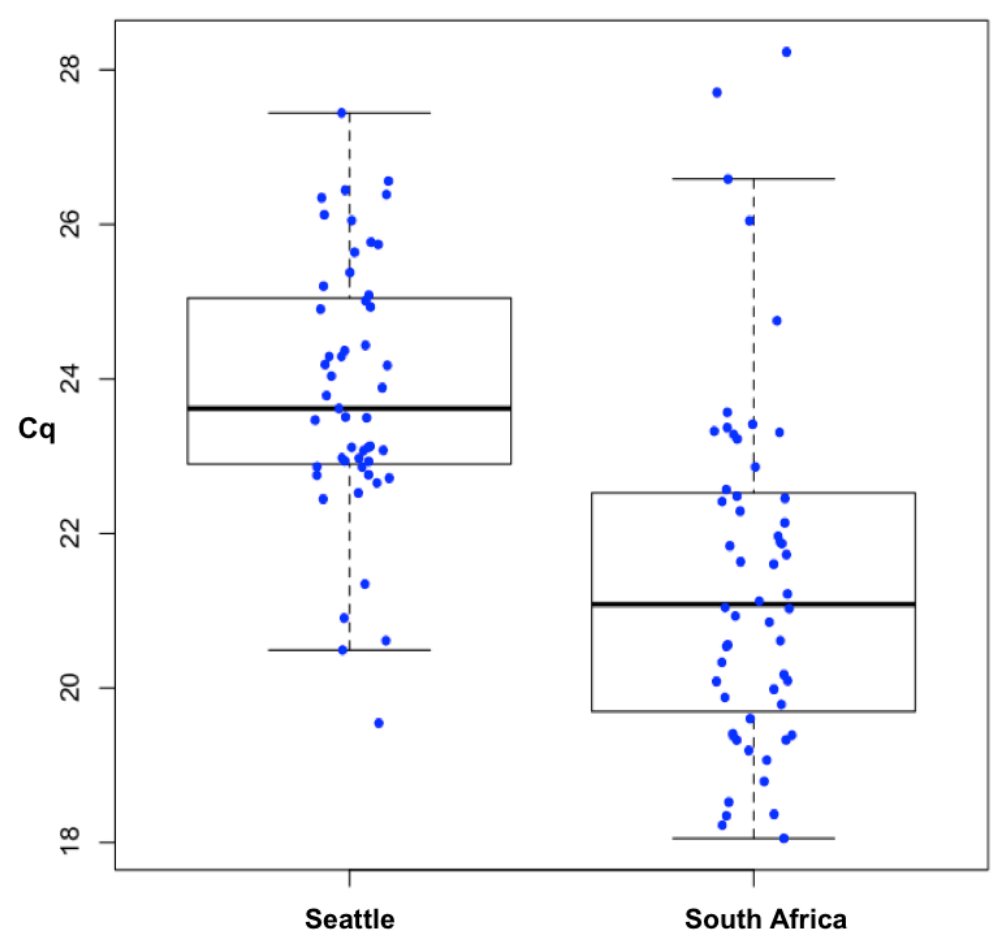

Figure 2. The mtDNA qPCR Cq differences between buccal OmniSwabs from the Seattle as compared to South African Participants

In evaluating sample adequacy at the previously calculated cutoff, 287/292 (98.2\%) of samples were correctly classified by $\mathrm{Cq}$ value. $100 \%$ of air controls swabs had Cq values above the 31.3 cutoff. Of the 5 mouth swabs that were incorrectly classified, 3 were PurFlock left buccal swabs, one was a gum swab and one was a tongue swab. There are many possible explanations for the $\mathrm{Cq}$ value results above the cutoff. First of all, it is possible that the mtDNA assay is reflecting sample adequacy, and the swabs that were incorrectly classified were indeed insufficiently sampled or had no mouth contact. It should be noted that both air control and left buccal swabs were PurFlock swabs, whereas the other mouth swabs were OmniSwabs, so a labeling error is possible. 
Secondly, a laboratory error is likewise possible. Finally, the mutability of the mitochondrial genome has been documented and affects about 11.5/100,000 individuals and variation within the qPCR target sequence could lead to a negative result. ${ }^{24}$ This seems unlikely considering the limited number of participants $(\mathrm{n}=70)$. Moreover, in the case swabs with a Cq value above the cutoff, the same participants had multiple swabs tested and others were below the Cq cutoff, indicating a mitochondrial sequence consistent with the consensus sequence at the targeted site.

Table 2. Proportion of samples correctly classified according to the previously calculated $\mathrm{Cq}$ cutoff. Paired comparisons of swabs different mouth regions and between two different swab types. All analyses were compared to buccal OmniSwabs.

\begin{tabular}{llll}
\hline & $\begin{array}{l}\text { Samples with } \\
\text { Cq<31.3/Total (\%) }\end{array}$ & $\begin{array}{l}\text { Human mtDNA } \\
\text { Cq average (SD) }\end{array}$ & P-value \\
\hline Cheek Omni** & $55 / 58(100 \%)$ & $21.9(2.6)$ & -- \\
Cheek PurFlock & $49 / 52(94.2 \%)$ & $20.6(3.9)$ & $\mathbf{0 . 0 3 5} * *$ \\
Tongue Omni & $53 / 54(98.4 \%)$ & $22.0(2.7)$ & 0.52 \\
Gum Omni & $63 / 64(98.1 \%)$ & $21.5(3.2)$ & 0.89 \\
Air Control & $64 / 64(100 \%)$ & $38.9(2.0)$ & - \\
Totals & $287 / 292(98.3 \%)$ & -- & - \\
\hline
\end{tabular}

Comparing OmniSwabs of different mouth regions, Cq values for gum or tongue swabs were not significantly different from buccal swabs (Table 2). Comparing swab types, Purflock buccal swabs yielded lower Cq values (indicating more human mtDNA) than OmniSwab buccal swabs $(\mathrm{p}=0.035)$. Thus, it appears that PurFlock swabs collect slightly more human biological material than OmniSwabs in the same mouth region.

Regression was performed to analyze the uniformity of $\mathrm{Cq}$ values across participant characteristics of HIV status, TB status as well as gender (Table 3). Four general linear model, one for each sample type of right cheek OmniSwab, left cheek Purflock swab, tongue swab and gum swab were evaluated no coefficients were found to be significantly different from the intercept. 
Table 3. General linear models for each of the sample types.

\begin{tabular}{lllll}
\hline & \multicolumn{4}{l}{ Sample Type and coefficient (t value) } \\
\hline Gender & Gum & Purflock & Right Omni & Tongue \\
HIV & $1.2(0.24)$ & $2.5(0.17)$ & $-0.13(0.86)$ & $-0.22(0.81)$ \\
TB & $-0.58(0.93)$ & $0.80(0.80)$ & $-0.43(0.77)$ & $1.2(0.051)$ \\
Gender + HIV & $-0.14(0.77)$ & $-2.4(0.41)$ & $0.30(0.82)$ & $2.9(0.66)$ \\
Gender + TB & $-2.01(0.53)$ & $-3.5(0.64)$ & $-0.039(0.99)$ & $-1.4(0.73)$ \\
HIV + TB & $-2.06(0.45)$ & $-0.17(0.97)$ & $2.0(0.30)$ & $-3.4(0.104)$ \\
All & $-1.6(0.70)$ & $-0.82(0.90)$ & $-3.7(0.20)$ & $0.45(0.90)$ \\
\hline
\end{tabular}

In summary, a sample adequacy control in the form of a qPCR assay targeting human mtDNA was able to distinguish properly from improperly collected oral swab samples and when implemented in a clinical cohort allowed for comparison of different sampling strategies independent of the diagnostic target.

\section{LIMITATIONS}

For the sample adequacy control study, samples were only collected from populations in Seattle and South Africa, and thus results may not be generalizable to other geographic regions.

Additionally, for the Seattle phase of the sampling I was unblinded as to the status of the swabs I was testing (whether they were from a hand or mouth). I was, however, blinded as to the status (air or mouth control) for the South African derived swabs. 


\section{MATERIALS AND METHODS}

Study Sites. Seattle. Subjects from the Seattle portion of the study were recruited by flyers and emails that were posted and sent throughout the UW campus.

South Africa. Samples from the South African portion of the study derive from participants recruited from clinics in Worcester (population 350,000), a rural area 1.5 hours outside of Cape Town. These samples were collected in partnership with the South African Tuberculosis Vaccine Initiation (SATVI) whose staff carries out the sample collection, shipments of samples, and training of support team and staff.

Human Oral Swab Collection. In Seattle, samples were collected by brushing Whatman OmniSwabs ${ }^{\mathrm{TM}}$ along the inside of the subject's cheek or the surface of their palm and fingers 7-8 times. OmniSwabs ${ }^{\mathrm{TM}}$ and PurFlock ${ }^{\mathrm{TM}}$ swabs were collected in South Africa by brushing the inner surface of the tongue, gums, or right cheek for 10 seconds $\left(\mathrm{OmniSwabs}^{\mathrm{TM}}\right)$, and the left inner cheek for the same duration (PurFlock ${ }^{\mathrm{TM}}$ ). Air controls were collected at both study sites by exposing a swab to air for 10 seconds (PurFlock ${ }^{\mathrm{TM}}$ in Worcester, OmniSwab ${ }^{\mathrm{TM}}$ in Seattle). Immediately following sampling, all swab heads were ejected into $500 \mathrm{~mL}$ of a lysis/preservation buffer ( $\mathrm{pH} 8.0$ ) consisting of $50 \mathrm{mM}$ EDTA and sucrose, $100 \mathrm{mM}$ sodium chloride, $65 \mathrm{mM}$ tris, and $0.3 \%$ SDS.

DNA extraction. Collected samples were frozen at $-80^{\circ} \mathrm{C}$ until extraction. Briefly, the extraction involved boiling swabs in lysis buffer at $100^{\circ} \mathrm{C}$ for $10 \mathrm{~min}$, followed by addition of proteinase $\mathrm{K}$ and QIAGEN lysis buffer AL and a 10 min incubation at $56^{\circ} \mathrm{C}$. Ethanol was then added to the samples and they were transferred to a plate column well for binding, two washes and an elution step, according to the QIAGEN 96 DNeasy Blood and Tissue Kit protocol. For the South African samples, extraction steps were identical except individual spin columns from the QIAGEN 
QIAmp DNA Mini Kit were substituted for the plate columns.

Quantitative PCR. Each sample collected in Seattle was tested twice, once with each optimized PCR protocol. A streptococcal qPCR was adapted using primers from Picard et al. ${ }^{25}$ with the addition of a hydrolysis probe specific for four species of streptococci, S. gordonii, S. mitis, S. pneumoniae and S. sanguinis. These streptococcal species were selected because of their established presence in the oral microbiome, combined with a limited known presence on the skin or in the environment. (http://www.homd.org/, http://hmpdacc.org/HMRGD/) The buffer and primer concentrations remained identical to the published protocol, with the modifications of probe concentration at $0.5 \mu \mathrm{M}$ in the final reaction mixture and $2 \mu \mathrm{L}$ of template instead of $1 \mu \mathrm{L}$. The mitochondrial PCR was adapted from Caldwell et al. ${ }^{26}$ For the set of samples from South Africa, $5 \mu \mathrm{L}$ of extracted DNA was tested only by the assay targeting human mtDNA.

Statistical Analyses. All statistical calculations were carried out using R, version 3.1.3. The package OptimalCutpoints was used to calculate Cq cutoffs with Youden's index. T-tests for both Seattle and South African studies were paired because they evaluated within subject differences. General linear models were generated to ascertain if participant characteristics were significant predictors for human mtDNA Cq results. Four models were constructed; one for gum swab results, one for tongue swab results, and one for each of left and right buccal swabs consisting of a PurFlock ${ }^{\mathrm{TM}}$ or OmniSwab ${ }^{\mathrm{TM}}$ respectively. The participant characteristics were analyzed for their ability to predict $\mathrm{Cq}$ values, both independently and in concert with one another.

Sample size. In order to resolve between sensitivity differences at each cutoff of $100 \%$ for the human mtDNA assay as compared to $99 \%$ for the streptococcal assay, 776 participants would be required. To ascertain if the paired differences from the cutoff for the mitochondrial test were less than streptococcal test with 0.8 power and a small effect size (0.2), 156 pairs are required (204 
pairs were used). For the paired analyses carried out for the South African samples, the sample size required to find the 0.5 effect size for differences in Cq between PurFlock ${ }^{\mathrm{TM}}$ and $\mathrm{Omni}^{\mathrm{TM}}$ buccal swabs, 30 pairs are required.

Table 4. Technical qPCR information for every qPCR assay used in the scope of work

\begin{tabular}{|c|c|c|c|}
\hline PCR TARGET & SEQUENCE (5'-3') & $\begin{array}{l}\text { Thermocycling } \\
\text { Conditions }\end{array}$ & Ref. \\
\hline $\begin{array}{l}\text { Segment of } \\
\text { Streptococcal } \\
\text { Tuf gene }\end{array}$ & $\begin{array}{l}\text { Str1- GTACAGTTGCTTCAGGACGTATC } \\
\text { Str2 - ACGTTCGATTTCATCACGTTG } \\
\text { Probe- CGACCGTGGTATCGTTAAAGTCA }\end{array}$ & $\begin{array}{l}96^{\circ} \mathrm{C} \text { for } 10 \mathrm{~min} ; 40 \\
\text { cycles of } 95^{\circ} \mathrm{C} \text { for } 15 \mathrm{~s} \\
\text { and } 54^{\circ} \mathrm{C} \text { for } 30 \mathrm{~s}\end{array}$ & 21 \\
\hline $\begin{array}{l}\text { 195bp segment } \\
\text { of human } \\
\text { mitochondrial } \\
\text { NADH } \\
\text { dehydrogenase } \\
5 \text { gene }\end{array}$ & $\begin{array}{l}\text { Fwd- CAGCAGCCATTCAAGCAATGC } \\
\text { Rev- GGTGGAGACCTAATTGGGCTGATTAG } \\
\text { Probe- } \\
\text { TATCGGCGATATCGGTTTCATCCTCG }\end{array}$ & $\begin{array}{l}95^{\circ} \mathrm{C} \text { for } 2 \mathrm{~min} ; 40 \\
\text { cycles of } 94^{\circ} \mathrm{C} \text { for } \\
10 \mathrm{~s}, 60^{\circ} \mathrm{C} \text { for } 12 \mathrm{~s} \text {, and } \\
72^{\circ} \mathrm{C} \text { for } 10 \mathrm{~s} .\end{array}$ & 22 \\
\hline $\begin{array}{l}\text { MTBC IS6110 } \\
\text { insertion } \\
\text { element }\end{array}$ & $\begin{array}{l}\text { TBC F- GGGTAGCAGACCTCACCTATG } \\
\text { TBC R- AGCGTAGGCGTCGGTGA } \\
\text { TBC probe- FAM TCGCCTACGTGGCCTTT } \\
\text { MGBNFQ }\end{array}$ & $\begin{array}{l}95^{\circ} \mathrm{C} \text { for } 10 \mathrm{~min} ; 45 \\
\text { cycles of } 95^{\circ} \mathrm{C} \text { for } 15 \mathrm{~s} \\
\text { and } 60^{\circ} \mathrm{C} \text { for } 1 \mathrm{~min}\end{array}$ & 23 \\
\hline
\end{tabular}




\section{REFERENCES}

1. WHO | Disability-adjusted life years (DALYs). WHO. 2017.

http://www.who.int/gho/mortality_burden_disease/daly_rates/text/en/. Accessed May 22, 2017.

2. Engel GA, Wilbur AK, Westmark A, Horn D, Johnson J, Jones-Engel L. Naturally acquired Mycobacterium tuberculosis complex in laboratory pig-tailed macaques. Emerg Microbes Infect. 2012;1(10):e30. doi:10.1038/emi.2012.31.

3. Spengler JR, Chakrabarti AK, Coleman-Mccray JD, et al. Utility of Oral Swab Sampling for Ebola Virus Detection in Guinea Pig Model. doi:10.3201/eid2110.150840.

4. Yang CJ, Chang SY, Wu BR, et al. Unexpectedly high prevalence of Treponema pallidum infection in the oral cavity of human immunodeficiency virus-infected patients with early syphilis who had engaged in unprotected sex practices. Clin Microbiol Infect.

2015;21(8):e787.e1-787.e7. doi:10.1016/j.cmi.2015.04.018.

5. Drobnik A, Judd C, Banach D, Egger J, Konty K, Rude E. Public health implications of rapid hepatitis $\mathrm{C}$ screening with an oral swab for community-based organizations serving high-risk populations. Am J Public Health. 2011;101(11):2151-2155. doi:10.2105/AJPH.2011.300251.

6. Balán I, Frasca T, Ibitoye M, Dolezal C, Carballo-Diéguez A. Fingerprick Versus Oral Swab: Acceptability of Blood-Based Testing Increases If Other STIs Can Be Detected. AIDS Behav. 2017;21(2):501-504. doi:10.1007/s10461-016-1497-4.

7. Kim W, Park HK, Hwang WJ, Shin HS. Simultaneous detection of streptococcus Pneumoniae, s. mitis, and s. oralis by a novel multiplex PCR assay targeting the gyrB gene. J Clin Microbiol. 2013;51(3):835-840. doi:10.1128/JCM.02920-12. 
8. Hang D, Liu F, Liu M, et al. Oral human papillomavirus infection and its risk factors among 5,410 healthy adults in China, 2009-2011. Cancer Epidemiol Biomarkers Prev. 2014;23(10):2101-2110. doi:10.1158/1055-9965.EPI-14-0084.

9. Aschar M, de Oliveira ETB, Laurenti MD, et al. Value of the oral swab for the molecular diagnosis of dogs in different stages of infection with Leishmania infantum. Vet Parasitol. 2016;225:108-113. doi:10.1016/j.vetpar.2016.06.005.

10. Erickson BR, Sealy TK, Flietstra T, et al. Ebola Virus Disease Diagnostics, Sierra Leone: Analysis of Real-time Reverse Transcription-Polymerase Chain Reaction Values for Clinical Blood and Oral Swab Specimens. J Infect Dis. 2016;214(suppl 3):S258-S262. doi:10.1093/infdis/jiw296.

11. Sia IG, Wieland ML. Current Concepts in the Management of tuberculosis. Clin Proc. 2011;86(4). doi:10.4065/mcp.2010.0820.

12. Global Tuberculosis Report 2015. http://apps.who.int/iris/bitstream/10665/191102/1/9789241565059_eng.pdf?ua=1. Accessed April 26, 2016.

13. Engel G, Wilbur AK, Jones-Engel L. How well do you know your monkey TB model? $J$ Med Primatol. 2013;42(1):46-47. doi:10.1111/jmp.12030.

14. Rosenbaum M, Mendoza P, Ghersi BM, et al. Detection of Mycobacterium tuberculosis Complex in New World Monkeys in Peru. Ecohealth. 2015;12(2):288-297. doi:10.1007/s10393-014-0996-x.

15. Wilbur AK, Engel GA, Rompis A, et al. From the Mouths of Monkeys: Detection of Mycobacterium tuberculosis Complex DNA From Buccal Swabs of Synanthropic Macaques. Am J Primatol. 2012;74(7):676-686. doi:10.1002/ajp.22022. 
16. Wood RC, Luabeya AK, Weigel KM, et al. Detection of Mycobacterium tuberculosis DNA on the oral mucosa of tuberculosis patients. 2015:1-5. doi:10.1038/srep08668.

17. Espy MJ, Uhl JR, Sloan LM, et al. Real-Time PCR in Clinical Microbiology : Applications for Routine Laboratory Testing. Clin Microbiol Rev. 2006;19(1):165-256. doi:10.1128/CMR.19.1.165.

18. Emmadi R, Boonyaratanakornkit JB, Selvarangan R, et al. Molecular methods and platforms for infectious diseases testing: A review of FDA-approved and cleared assays. $J$ Mol Diagnostics. 2011;13(6):583-604. doi:10.1016/j.jmoldx.2011.05.011.

19. Sepúlveda D, Bohle H, Labra Á, et al. Design and evaluation of a unique RT-qPCR assay for diagnostic quality control assessment that is applicable to pathogen detection in three species of salmonid fish. BMC Vet Res. 2013;9(1):183. doi:10.1186/1746-6148-9-183.

20. Bristow CC, Adachi Kristina, Karin Nielsen-Saines, et al. Characteristics of the Sample Adequacy Control (SAC) in the Cepheid Xpert ${ }^{\circledR}$ CT/NG Assay in Female Urine Specimens. J Microbiol Exp. 2014;1(4):1-5. doi:10.15406/jmen.2014.01.00026.

21. Barroso E, Martín V, Martínez-Cuesta MC, Peláez C, Requena T. Stability of saliva microbiota during moderate consumption of red wine. Arch Oral Biol. 2015;60(12):17631768. doi:10.1016/j.archoralbio.2015.09.015.

22. Kamodyova N, Minarik G, Hodosy J, Celec P. Single consumption of Bryndza cheese temporarily affects oral microbiota and salivary markers of oxidative stress. Curr Microbiol. 2014;69(5):716-724. doi:10.1007/s00284-014-0649-x.

23. Hegde MC, Kumar A, Bhat G, Sreedharan S. Oral Microflora: A Comparative Study in HIV and Normal Patients. Indian J Otolaryngol Head Neck Surg. 2014;66(SUPPL.1):126132. doi:10.1007/s12070-011-0370-z. 
24. Tuppen HAL, Blakely EL, Turnbull DM, Taylor RW. Mitochondrial DNA mutations and human disease. Biochim Biophys Acta - Bioenerg. 2010;1797(2):113-128. doi:10.1016/j.bbabio.2009.09.005.

25. Picard FJ, Ke D, Boudreau DK, et al. Use of tuf sequences for genus-specific PCR detection and phylogenetic analysis of 28 streptococcal species. J Clin Microbiol. 2004;42(8):3686-3695. doi:10.1128/JCM.42.8.3686-3695.2004.

26. Caldwell JM, Raley ME, Levine JF, Levine J a YF. Mitochondrial Multiplex Real-Time PCR as a Source Tracking Method in Fecal-Contaminated Effluents Mitochondrial Multiplex Real-Time PCR as a Source Tracking Method in Fecal-Contaminated Effluents. Environ Sci Technol. 2007;41(9):3277-3283. doi:10.1021/es062912s.

27. Inangolet FO, Demelash B, Oloya J, Opuda-Asibo J, Skjerve E. A cross-sectional study of bovine tuberculosis in the transhumant and agro-pastoral cattle herds in the border areas of Katakwi and Moroto districts, Uganda. Trop Anim Health Prod. 2008. doi:10.1007/s11250007-9126-X.

28. Bezos J, Casal C, Romero B, et al. Current ante-mortem techniques for diagnosis of bovine tuberculosis. Res Vet Sci. 2014;97:S44-S52. doi:10.1016/j.rvsc.2014.04.002.

29. Halse TA, Edwards J, Cunningham PL, et al. Combined real-time PCR and rpoB gene pyrosequencing for rapid identification of Mycobacterium tuberculosis and determination of rifampin resistance directly in clinical specimens. J Clin Microbiol. 2010;48(4):11821188. doi:10.1128/JCM.02149-09.

30. Araújo CP, Osório ALAR, Jorge KSG, et al. Detection of Mycobacterium bovis in Bovine and Bubaline Tissues Using Nested-PCR for TbD1. Inacio J, ed. PLoS One. 2014;9(3):e91023. doi:10.1371/journal.pone.0091023. 
31. Sotnikova EA, Shitikov EA, Malakhova M V, et al. Complete Genome Sequence of Mycobacterium bovis Strain BCG-1 (Russia).

32. Zheng H, Lu L, Wang B, et al. Genetic Basis of Virulence Attenuation Revealed by Comparative Genomic Analysis of Mycobacterium tuberculosis Strain H37Ra versus H37Rv. Davis D, ed. PLoS One. 2008;3(6):e2375. doi:10.1371/journal.pone.0002375. 


\section{APPENDIX A. Nasal Swabs for Detection of Bovine Tuberculosis}

\section{a. Background}

Tuberculosis is often regarded in terms of its substantial threat to human health but what is often overlooked is the potential role of animals and the environment in the transmission of this disease. The concept of "One Health" takes the holistic approach of considering relationships between humans, animals and the environment in the ecology of disease in order to reach a speciesspanning goal of health. Historically and presently, tuberculosis has been a disease problem for livestock. While the primary causative agent for tuberculosis in cattle (Mycobacterium bovis) differs slightly from the human TB pathogen (Mycobacterium tuberculosis), humans can be infected with $M$. bovis and cattle can contract M. tuberculosis. While mostly eliminated in highincome countries, $M$. bovis is still prevalent in low and middle-income countries in humans, domestic, and sylvatic animals (wildlife), though to what extent remains unknown. ${ }^{27}$

One of the barriers to determining the prevalence of $M$. bovis in animals is the low performance of current tools in use for diagnosing bTB. Current ante-mortem diagnostic techniques include an intradermal tuberculin test (recognized by the World Organization of Animal Health as the primary screening test), interferon gamma release assay, lymphocyte proliferation assay, and serological assays. The intradermal tuberculin test is the diagnostic method that has been in use for the longest time and still remains the standard in most areas. The method involves dermal injection of heat-treated and lysed M. bovis AN5 (bovine PPD), with an assessment of swelling 72 hours later. Sensitivity of the PPD for diagnosing TB infection in cattle has been estimated using a Bayesian model to be between 53-69.4\% based on previous studies and depending on interpretation criteria. A number of studies have placed the specificity of the test between 51.1 and over $99 \%$ with a median of $95 \%{ }^{28}$ 
Though not yet widely adopted or standardized, the use of molecular based tests for detection of M. bovis has been reported. The performance of these assays appears to vary based on the genetic target of the assay and the type of sample tested. Table 5 summarizes several of these reports. Further complicating the issue is the lack of a gold standard for bovine tuberculosis diagnosis, especially as a point of comparison with nasal swabs. Kao et al. evaluated TB shedding patterns in experimentally infected calves and found that shedding was intermittent, even among infection with the same strain. Their results suggest a shedding pattern consistent with an infection model in which bacilli are concentrated in foci (not equivalent to granulomas), and organisms with more severe infection, and thus shedding, have more foci. ${ }^{15}$ Thus the correlation between antigenic positivity (PPD status) and qPCR nasal swab result is as yet undetermined, as is the ability of nasal swab molecular testing to detect TB in actively shedding animals.

Table 5. Summary of past studies utilizing nasal swab qPCR for bovine tuberculosis detection.

\begin{tabular}{llll}
\hline Author & N (PPD) & Samples & Results \\
\hline Akhtar et al. & $\begin{array}{l}53 \text { cows and buffalo } \\
(\mathrm{PPD}+)\end{array}$ & $\begin{array}{l}\text { Nasal swabs } \\
\text { Milk }\end{array}$ & $\begin{array}{l}\text { Nasal Swabs }-68 \%(36 / 53) \\
\text { Milk }-(34 / 53) 64 \%(\mathrm{MTC}-\mathrm{MPB} 70)\end{array}$ \\
Romero et al. & $\begin{array}{l}30 \text { cows } \\
(\mathrm{PPD}+)\end{array}$ & Nasal exudate & $26 \%(8 / 30)$ \\
Meikle et al. & $\begin{array}{l}14 \text { cows } \\
(\mathrm{PPD}+)\end{array}$ & Nasal swabs & $\begin{array}{l}\text { Month } 7-50 \%(7 / 14)(\text { IS6110) } \\
\text { Month } 9-90 \%(9 / 10),(4 \text { not done })\end{array}$ \\
Cedeno et al. & $\begin{array}{l}60 \text { cows } \\
(\text { Only } 3 \text { PPD }+)\end{array}$ & Nasal swabs & $65 \%(39 / 60)$ \\
Kao et al. & $\begin{array}{l}12 \text { calves } \\
\text { experimentally infected }\end{array}$ & Nasal exudate & $\begin{array}{l}\text { Culture based - Propose a foci-based } \\
\text { shedding pattern }\end{array}$ \\
\hline
\end{tabular}

\section{b. Methods}

For this project, the oral swab analysis method was adapted and evaluated in a bovine population. 
The goal of this part of the project was to evaluate if nasal swabs could detect bovine tuberculosis in PPD positive cows (indicating exposure to tuberculosis), adding to the work of the studies summarized in table 5. Considering the ease with which oral swabs may be collected and transported, and the prior use of OSA in sampling primates, molecular testing of nasal swabs could provide a simple and sensitive easy way of detecting TB bacilli in cattle.

Cattle were recruited from Moyo and Adjumani districts in Northern Uganda. A caudal fold PPD test was performed and after 72 hours, if a positive result was read, nasal swabs were taken from these cattle by brushing Whatman OmniSwabs in the interior of the nostril 7-8 times ( $\mathrm{n}=19)$. Swabs were then boiled and were stored at $-80{ }^{\circ} \mathrm{C}$ until shipment to Seattle. Bovine nasal swabs were extracted identically to South African oral swabs. Bovine nasal swabs were then tested by a qPCR targeting IS6110, an insertion element present in members of the MTBC adapted from Halse et al. ${ }^{29}$ Further testing was conducted on these samples, first to evaluate whether qPCR inhibition was occurring and second for an M. bovis specific target to ensure that qPCR positives were not due to laboratory contaminationThey were later tested by a nested qPCR which targeted the TbD1 region adapted from Araujo et al..$^{30}$ PCR primer and probe sequences as well as thermocycling conditions are summarized in Table 4.

Based on diagnostic yields reported from past studies, a low estimate of positive swabs in PPD positive cattle was estimated at $25 \%$. Assuming $25 \%$ of PPD positives are $\mathrm{qPCR}$ positive, and $1 \%$ of PPD negative are qPCR positive, 31 cattle are required for significance at 0.05 and $80 \%$ power. Only 19 swabs were able to be collected, thus 4-5 positives are expected 


\section{c. Results and Discussion}

When initially tested by qPCR targeting IS6110 for M. tuberculosis complex (MTBC) bacteria, 5 out of 19 bovine nasal swab samples yielded a positive result (Figure 4). Cq values from positive samples ranged from 38.1 to 41.6 with an average of 39.8. These $\mathrm{Cq}$ values are consistent low amounts of target DNA, however there are many explanations for this. First of all, M. bovis has fewer copies of the IS6110 element as compared to most M. tuberculosis strains. For $M$. tuberculosis H37Ra strain has 17 copies as compared to only 1 in many strains of M. bovis. ${ }^{31,32}$ Secondly, the samples were shipped and stored at room temperature for several months, making sample degradation a possible reason for lower Cq values. Finally, lower Cq values can sometimes indicate laboratory contamination as a reason for positive results. A confirmatory assay was undertaken to rule this out as a reason for the positive results.

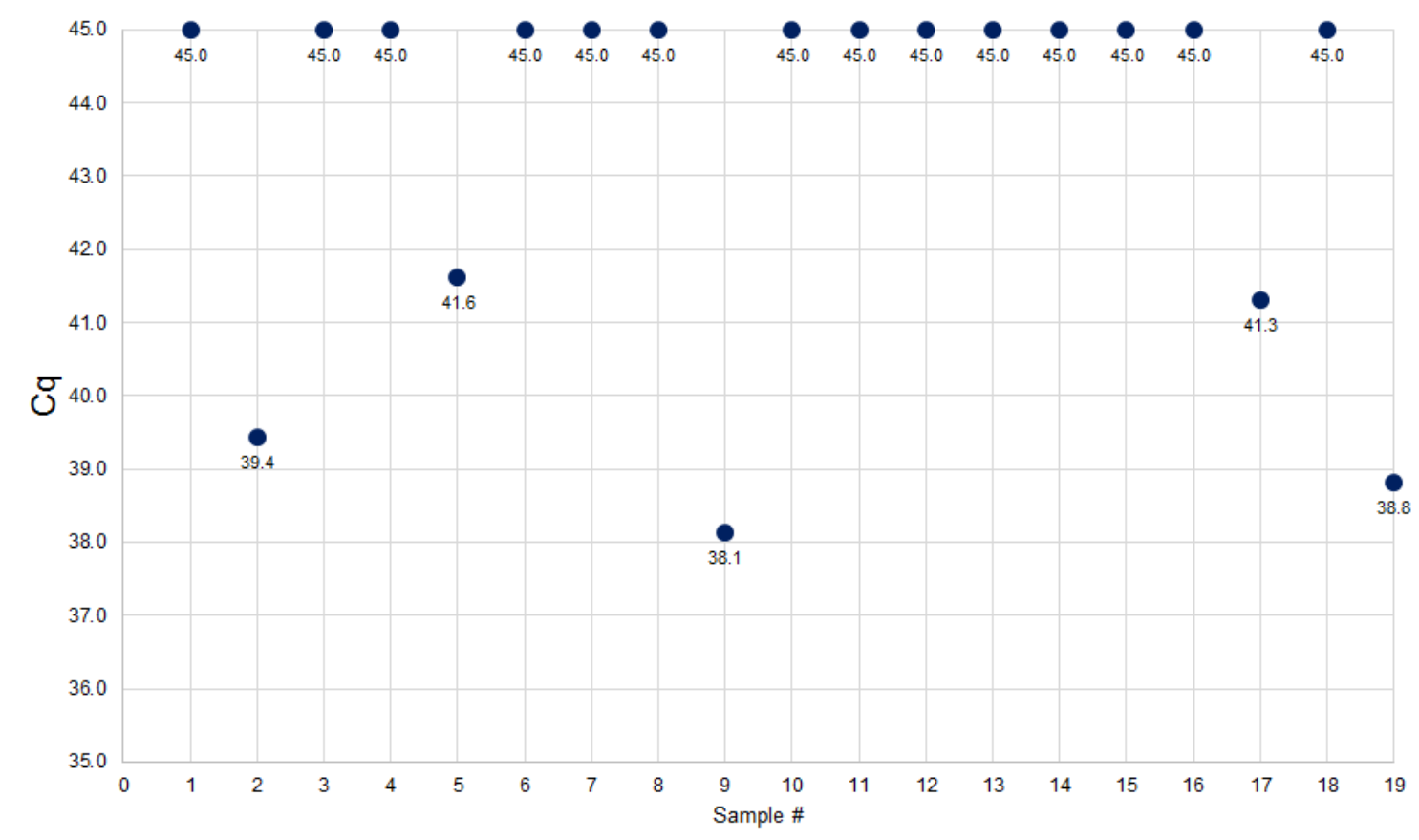

Figure 4. Initial Cq results for qPCR for IS6110 in Bovine Nasal Swabs 
To determine whether inhibitive elements present in the nasal swab samples were causing false negative results or deterring sensitivity, an experiment was conducted in which $0.1 \mathrm{pg} \mathrm{H} 37 \mathrm{Ra}$ DNA was added into 6 nasal swab samples, which had been negative in the previous qPCR targeting IS6110. DNA was added at different stages of the extraction procedure to further deduce the nature of the inhibition, if it was occurring. For 3 samples, the DNA was added prior to transfer onto the spin column, while for the other 3, DNA was added at the end of extraction and precipitation. Cq values from spiked nasal swabs had an average of 31.5 as compared to 31.6 for the positive controls. These two groups were not significantly different $(\mathrm{p}=0.89)$. Inhibitive substances present in nasal swab are thus not a likely reason for negative results from IS6110 qPCR.

In summary, in the absence of a suitable confirmatory assay, it is unclear whether initial laboratory results are true positives or due to laboratory contamination. In light of ability to detect bovine tuberculosis as demonstrated in previous studies, further evaluation of the use of nasal swab qPCR in detecting bovine tuberculosis is warranted. 